\title{
A LEI DE ACESSO À INFORMAÇÃO ENQUANTO INSTRUMENTO FACILITADOR DA CIDADANIA ATRAVÉS DO USO DE TICS
}

\section{THE LAW ACCESS INFORMATION AS INSTRUMENT FOMENT OF CITIZENSHIP THROUGH THE USE OF ICT}

\author{
${ }^{1}$ Aline Martins Rospa
}

\section{RESUMO}

Os entes estatais passam pelo contínuo desafio de se adaptar às novas realidades trazidas pela globalização e sociedade de informação, na qual o uso das tecnologias de informação e comunicação modificaram a forma do poder público cumprir as suas obrigações. A promulgação de leis específicas garantindo o acesso às informações públicas visa incentivar a participação popular no sentido de efetivar mudanças necessárias no comportamento do poder público, que deve priorizar ao máximo a transparência na divulgação das informações públicas. Empregou-se o método dedutivo para direcionar a pesquisa documental e doutrinária sobre o direito ao acesso à informação pública.

Palavras Chaves: Acesso à informação; internet; cidadania; participação popular; tecnologias da informação e comunicação.

\begin{abstract}
The State pass through the ongoing challenge to adapt to the new realities brought about by globalization and the information society, in which the use of information and communication technologies have changed the way the government meet its obligations. The promulgate of specific laws guaranteeing access to public information aims to encourage popular participation in order to effect necessary changes in government behavior, which should prioritize the maximum transparency in the disclosure of public information. It used the deductive method to direct documentary and doctrinal research on the right to access to public information.
\end{abstract}

Keywords: Access to information; internet; citizenchip; popular participation; information and communication technologies.

\footnotetext{
${ }^{1}$ Mestranda em Direito pela Universidade Federal de Santa Maria - UFSM, Rio Grande do Sul, (Brasil). Área de concentração: Direitos Emergentes na Sociedade Global, Linha de pesquisa: Direitos na Sociedade em Rede. Advogada. E-mail: alinerospa@gmail.com
} 


\section{INTRODUÇÃO}

O meio virtual cresce a cada dia como instrumento de aquisição de conhecimento e formação de opinião da sociedade, e também como mecanismo de participação popular reforçando as bases da democracia brasileira. Com a internet houve uma ampliação da liberdade de expressão e a possibilidade de as pessoas exercitarem sua cidadania e seu poder de ação por meio dos novos mecanismos virtuais disponibilizados, ensejando a participação democrática.

No contexto da ampliação do exercício da cidadania, a lei de acesso à informação (Lei 12.529/2011), impactou positivamente no cenário jurídico brasileiro aumentando o rol de possibilidades dos cidadãos terem acesso ao conteúdo de decisões políticas que implicam, principalmente, na destinação de verbas públicas.

Necessário então analisar se, de fato, a LAI facilitou o acesso à informação, enquanto componente do direito fundamental à liberdade de expressão. Portanto, para promover o exercício da democracia, o direito ao acesso à informação deve garantir e incentivar a interação entre governo e cidadão.

Nessa medida, para ampliar o espaço democrático, os governos devem aproveitar o progresso que o uso das tecnologias de informação lhes apresenta para proporcionar ao cidadão um efetivo poder de ação e fiscalização. Todavia, para tanto, é necessário que seja operabilizado um sistema de transparência que garanta, efetivamente, o acesso à informação dotada de veracidade e integridade.

Utilizou-se o método dedutivo para direcionar a pesquisa documental e doutrinária sobre o direito ao acesso à informação pública, assim como para compreender as transformações provocadas pela globalização e o uso das tecnologias de informação e comunicação no Estado.

\section{A AUTONOMIA DO DIREITO AO ACESSO À INFORMAÇÃO EM RELAÇÃO AO DIREITO À LIBERDADE DE EXPRESSÃO}

A doutrina clássica ensina que a promulgação de uma nova Constituição é ao mesmo tempo uma reação ao passado e um compromisso com o futuro (SARLET, 2006, p. 71). Foi exatamente com este espírito que os constituintes elaboraram a Carta Magna de 1988, 
reservando ao tema da liberdade de expressão a devida atenção, uma vez que o país havia, a pouco tempo, saído de uma situação ditatorial.

A liberdade de expressão pode ser observada como um mecanismo da democracia, uma vez que possibilita o pluralismo de manifestações. Aliás, para que um sistema seja considerado democrático são necessários alguns requisitos mínimos como: pluripartidarismo; liberdade de opinião e pensamento; direito de votar e ser votado, em sigilo; valor igual para os votos e eleições periódicas (LARA, 2013, p. 13).

Nesse sentido, Saldanha ressalta que a liberdade de expressão não é apenas um valor instrumental ou um meio para um fim mais importante, pelo contrário, esta liberdade é, em si, um direito humano fundamental, sendo este elemento indispensável para um regime democrático (2013, p. 186). A importância da liberdade de expressão é justificada, em grande parte, por servir de instrumento ao controle da atividade governamental e do exercício do poder.

A liberdade de expressão está positivada no art. 5, IX da Constituição Federal, que estabelece ser livre a expressão de atividade intelectual, artística, científica e de comunicação, independentemente de censura ou licença.

Já no cenário internacional, merece destaque a primeira emenda à Constituição dos Estados Unidos da América, que foi redigida pelo Congresso dos EUA em 1789 e ratificada pelos estados em 15 de dezembro de 1791:

O Congresso não legislará no sentido de estabelecer uma religião, ou proibindo o livre exercício dos cultos; ou cerceando a liberdade de palavra, ou de imprensa, ou o direito do povo de se reunir pacificamente, e de dirigir ao Governo petições para a reparação de seus agravos.

O direito à liberdade de expressão sempre foi defendido com persistência no sistema norte-americano, prevalecendo, muitas vezes, em relação aos direitos da personalidade. A Constituição dos EUA protege, inclusive, o discurso mais crítico ao governo, pois entende que cidadãos que possuam autonomia e liberdade para poder se expressar livremente formarão as bases de um Estado transparente e representativo.

Ainda no âmbito internacional, o Pacto de São José da Costa Rica de 1969, do qual o Brasil é signatário, defende em seu art. 13 que:

Toda pessoa tem direito à liberdade de pensamento e expressão. Este direito compreende a liberdade de buscar, receber e difundir informações e ideias de toda 
índole, sem consideração de fronteiras, verbalmente ou por escrito, ou em forma expressa ou artística, ou por qualquer outro processo de sua escolha.

Assim como esses, inúmeros outros documentos e cartas de direitos humanos elencam o direito à liberdade de expressão como peça fundamental de um Estado democrático de Direito, o que ressalta a extensão desse direito que ao longo da história sofreu com agressões e desrespeito de entes estatais despóticos.

Logo, o que se observa, é uma tentativa de solidificação da teoria de que um Estado nunca será democrático se não permitir que sua população tenha ampla liberdade de receber e transmitir informações. James Madison, mentor da Primeira Emenda da Constituição dos Estados Unidos, entendia que a principal finalidade da liberdade de expressão e comunicação era servir de instrumento para a soberania popular construir e manter um autogoverno democrático (FARIAS, 2004, p. 68).

A liberdade de expressão pertence ao núcleo essencial da existência humana. $\mathrm{O}$ homem somente pode existir como ser racional quando ele mesmo pode formar sua opinião e atuar de acordo com esta (FLEINER, 2003, p. 107). Por isso, é tão importante para a formação cultural da sociedade, que seja patrocinado e defendido o direito fundamental à liberdade de expressão.

Por ser um direito amplo, a liberdade de expressão possibilita que outros direitos fundamentais possam emergir através de suas lentes. Para Luis Roberto Barroso há distinção entre a liberdade de informação e de expressão, sendo a primeira referente ao direito individual de comunicar livremente os fatos e ao direito difuso de ser deles informado. Já a liberdade de expressão seria destinada a tutelar o direito de externar ideias, opiniões, juízos de valor, ou seja, qualquer manifestação do pensamento humano. Todavia, diz o autor, é inegável que a liberdade de informação se insere na liberdade de expressão em sentido amplo (2003, p. $35)$.

No mesmo sentido, entende André Ramos Tavares para quem a liberdade de expressão é um direito genérico, que abarca muitas formas e direitos conexos e que não pode ser restringido a um singelo externar de sensações ou intuições. Diz ainda que os direitos conexos ao gênero liberdade de expressão são: liberdade de manifestação de pensamento, de comunicação, de informação, de acesso à informação, de opinião, de imprensa, de mídia de divulgação e de radiodifusão (2005, p. 54).

Essa diferenciação entre a liberdade de expressão e o direito ao acesso à informação foi, aos poucos, sendo reconhecida. Com isso, os parlamentos passaram a elaborar 
leis específicas que regem o direito do cidadão ter acesso às informações públicas em posse do Estado.

A importância do direito ao acesso à informação está em promover a transparência e a possibilidade de controle social dos atos públicos. Por controle social, entende-se aquele exercício pela sociedade em que o cidadão individualmente ou representado por terceiro legitimado pode realizar denúncias para o Tribunal de Contas da União (SILVA; DE LA RUE, 2013, p. 412).

O acesso à informação pública é de fundamental relevância na medida em que, é através do conhecimento da máquina estatal, que envolve as despesas com o funcionalismo público, licitações, contratos públicos e, até mesmo, a produtividade dos agentes públicos, que a sociedade poderá entender e cobrar do Estado a prestação adequada e efetiva dos serviços públicos.

Os Estados autoritários, no que se refere à divulgação de informações públicas, são regidos por uma cultura de segredo, em que prevalece a máxima de que a circulação de informações representa riscos. Logo, são criados inúmeras exceções e empecilhos para dificultar a publicidade das informações.

Por outro lado, o que se espera de Estados democráticos é que haja uma cultura de acesso, em que os agentes públicos tenham consciência de que a informação pública pertence ao cidadão e que cabe ao Estado provê-la de forma clara e tempestiva para atender eficazmente às demandas da sociedade (CONTROLADORIA GERAL DA UNIÃO, 2011, P. 14).

Nesse contexto, Catalina Botero, relatora especial para liberdade de expressão da Corte Interamericana de Direitos Humanos ( $\mathrm{CIDH})$, ressalta que houve uma quebra de paradigma na década de 90, quando houve a passagem de um sistema fechado (cultura do segredo) para um sistema participativo (cultura da transparência) (BOTERO, 2014).

A restrição ao acesso à informação, portanto, impede que a população compreenda e exija a realização de políticas públicas voltadas à educação, saúde, assistência social, trabalho, dentre outras. A limitação à obtenção de informações públicas retira o direito do cidadão participar ativamente na construção do processo de decisão em temas que afetam diretamente seus direitos (SILVA; DE LA RUE, 2013, p. 411).

Portanto, reiterou-se a noção de que o direito ao acesso à informação pública é direito autônomo em relação ao direito à liberdade de expressão, sendo a promulgação de leis específicas de grande importância para incentivar a participação popular democrática no 
sentido de efetivar mudanças necessárias no comportamento do poder público, que deve priorizar ao máximo a divulgação das informações requeridas.

\section{A EXPANSÃO DA CIDADANIA ATRAVÉS DAS TECNOLOGIAS DA INFORMAÇÃO E COMUNICAÇÃO}

O meio virtual cresce a cada dia como instrumento de aquisição de conhecimento e formação de opinião da sociedade, e também como mecanismo de participação popular reforçando as bases da democracia brasileira. Tal fato pode ser demonstrado através dos últimos acontecimentos políticos ocorridos em solo nacional, em que se pode perceber o papel fundamental da rede ao possibilitar um espaço livre para as manifestações sociais, viabilizando a maciça participação popular, que se utiliza da internet como ferramenta.

Atualmente, os Estados são atingidos por uma nova conjuntura social, em que, pela abertura das fronteiras e pelos intercâmbios cada vez mais rápidos em um mundo global, a cultura não se restringe mais ao plano local, sendo profundamente influenciada por sugestões e informações vindas de toda a parte do mundo. As comunicações desenvolvem a imaginação e expandem o conhecimento e, é ele que nos conscientiza de nossas diferenças em relação aos outros, sendo a tecnologia o instrumento necessário para essa mudança (BAUMANN, 2016, p. 44).

O modelo estatal, forjado no Ocidente, está passando por transformações que não são superficiais ou cosméticas, mas que conduzem a novos pontos de equilíbrio. Essas transformações remetem a uma evolução global, com a redefinição da arquitetura social, em que será necessária a perda de antigas referências, a desagregação dos antigos moldes e o enfraquecimento das certezas (CHEVALLIER, 2009, p. 13).

Assim, a globalização possibilitou a circulação mais rápida de conhecimentos técnico-científicos, bem como o interesse pela cultura, economia e política de outros países. As tecnologias da informação também foram intensamente influenciadas pela globalização e, atualmente, são responsáveis pela ampla comunicação entre as pessoas de toda a parte do mundo.

Todavia, não se pode analisar apenas os pontos positivos desse processo que, sem dúvida, acelerou o crescimento da utilização das tecnologias de informação e comunicação. Necessário que se tenha conhecimento de que a globalização sofre diversas críticas por ter 
seus objetivos calcados basicamente nos lucros econômicos e deixar de lado o aspecto particular de cada sociedade, com a finalidade exclusiva do aumento dos bens de consumo.

Por isso, Milton Santos (2008, p. 16) afirma que as tentativas de construção de um só mundo sempre conduziram a conflitos, porque se tem buscado unificar e não unir. E o que rege a globalização não é uma vontade de liberdade, mas de dominação, não é o desejo de cooperação, mas de competição. A dimensão mundial, na verdade, são as organizações ditas mundiais: instituições supranacionais, organizações internacionais, universidades mundiais, meios de comunicação de massa, dentre outros.

Observa-se que as consequências da globalização, que ocorreram principalmente no âmbito econômico, tiveram reflexos também na dimensão cultural das sociedades, pois a internacionalização propiciou a homogeneização progressiva dos estilos de vida, dos modelos de consumo e dos padrões culturais SANTOS, 2008, p. 33).

Nesse novo contexto cultural e social, a internet tem se tornado, progressivamente, um meio importante de comunicação e organização em todas as esferas de atividade. Os movimentos sociais e o processo político a usam como um instrumento privilegiado para atuar, informar, recrutar, organizar, dominar e contradominar (CASTELLS, 2003, p. 114).

Os movimentos sociais a utilizam, principalmente, porque é a maneira que podem alcançar a sociedade como um todo. Isso porque, nessa situação, não dependem de espaço físico ou outras estruturas formais, o que pode facilitar o engajamento social, bem como sua organização.

Castells sustenta que esse tipo de movimentação social não é novidade na história da coletividade. A grande novidade é a interconexão desses movimentos com o uso da internet, uma vez que ela permite ao grupo ser diverso e coordenado ao mesmo tempo. Com isso, o próprio ambiente virtual é modificado de ferramenta organizacional para as empresas, sua função originária, para uma alavanca de transformação social e cultural (2003, p. 119).

Antes do advento da internet as manifestações de ideias e opiniões estavam aprisionadas aos meios tradicionais de comunicação, os quais, na maioria das vezes, grande parte da população não tinha acesso a se expressar, mas tão somente a se informar. Castells afirma que "as redes interativas de computadores estão crescendo exponencialmente, criando novas formas e canais de comunicação, moldando a vida e, ao mesmo tempo, sendo moldadas por ela" (2008, p. 40).

O exercício das liberdades individuais nunca foi gratuito, pelo contrário sempre demandou um esforço contínuo para ser capaz de redefinir a autonomia e exercer a 
democracia em cada contexto social e tecnológico. A internet, nesse cenário, possui um grande potencial para a expressão dos direitos dos cidadãos, pois ao ampliar as fontes de comunicação, contribui para a democratização.

A rede coloca as pessoas em contato para expressar suas inquietações e partilhar suas esperanças, por esse motivo o controle do ambiente virtual pelo povo, talvez, seja a questão política mais fundamental suscitada pelo seu desenvolvimento (CASTELLS, 2003, p. $135)$.

Justamente por esse motivo, a internet carrega alguns contrapontos em si, pois ao mesmo tempo em que possibilita a celeridade da liberdade de expressão aos sujeitos, pode ensejar dano a outros direitos de igual valor. A busca incessante pela celeridade na divulgação das informações pode, por vezes, prejudicar a avaliação da veracidade e integridade dos fatos e notícias divulgadas.

Nesse contexto, surge um novo meio de interação chamado ciberespaço, local em que há uma troca constante de dados particulares e públicos, os quais necessitam da presença do Direito para tutelar direitos ou reparar danos que, porventura, possam emergir desse ambiente.

O ciberespaço pode ser entendido como "o espaço de comunicação aberto pela interconexão mundial de computadores e das memórias dos computadores, sendo uma de suas principais funções prover o acesso a distância aos diversos recursos de um computador". Esse ambiente tem a capacidade de unir e interfacear todos os dispositivos de criação de informação, gravação, comunicação e simulação nas comunicações. Quanto à digitalização das informações, o autor profetizou que, provavelmente, o ciberespaço seria o principal canal de comunicação e suporte de memória da humanidade (LÉVY, 2000, p. 93).

Desse modo, a ciberdemocracia, ao atuar no ciberespaço auxilia a emancipar cada vez mais novos direitos, bem como incentivar a participação dos cidadãos que passam a desenvolver a cibercultura, cada vez mais rica e complexa e relacionada a novas práticas comunicativas, de exercício da democracia e, até mesmo, da fiscalização do Estado.

Nessa senda, conforme ensinamentos de Luño (2004, p. 41), a cibercidadania positiva é um instrumento de reconhecimento de incompletudes mútuas, apresentando-se como condição sine qua non de um diálogo intercultural (tanto na forma horizontal, entre cidadão/cidadão, quanto vertical, entre cidadão/Estado).

Por outro lado, é necessário que se ressalte a ideia de utilização consciente das tecnologias de informação e comunicação (TICs), as quais devem ser vistas como um meio 
integrante de um conjunto de instrumentos teóricos, metodológicos e políticos socialmente construídos na tentativa de realizar mudanças que sejam voltadas à efetivação de novos direitos. Nesse sentido, VELOSO sustenta que:

Para que as potencialidades presentes no uso das TIC adquiram concretude, é necessário um sólido processo de apropriação desse recurso, marcado pela valorização da competência crítica, e não apenas tecnológica. A apropriação das TIC a processos de trabalho pode assumir um caráter estratégico, possibilitando melhorias e avanços significativos nas diversas praticas às quais este recurso pode ser incorporado, proporcionando, dentre outros fatores, a viabilização de avanços na luta pela defesa de direitos, pela ampliação e consolidação da cidadania e pelo aprofundamento da democracia. Sem a garantia de tais pressupostos, o uso das tecnologias pode deixar de ser estratégico e cair na armadilha do tecnicismo (2011 p.11).

Como se observa, não se deve acreditar que as TICs aplicadas ao conceito de ciberdemocracia, sozinhas, têm o poder de resolver todos os problemas decorrentes da falta de representatividade dos cidadãos no Estado democrático. Por isso, defende-se a necessidade de adequação dos diversos setores da sociedade aos tempos digitais, incluindo-se o Estado, o qual deve fazer a utilização das TICs de modo a assegurar a democracia. Indo ao encontro do exposto, ROVER menciona que:

Os governos devem aproveitar o progresso que o uso das tecnologias de informação lhes apresenta para simplificar a burocracia estatal e proporcionar ao cidadão um poder de ação, superando as estruturas administrativas hierarquizadas e verticalizadas em direção a relações de poder horizontalizadas (2009, p.76).

Sob esse ponto de vista, pode-se concluir que as tecnologias de informação e comunicação realmente são aptas a permitir uma vasta rede de comunicações humanas facilitando a concretização das liberdades individuais e coletivas. Todavia, vistas sob outra ótica são também uma forma de controle generalizado por quem detém o poder político, econômico e o conhecimento cibernético.

Esse controle pode ser realizado tanto pelos Estados, ao interceptar as comunicações feitas pela internet, quanto pelo setor privado, que realiza a coleta de dados dos seus usuários (SALDANHA, 2013, p. 203). Logo, o uso do ciberespaço traz diversas consequências, tanto positivas, como facilitação do exercício das liberdades individuais, quanto negativas, como o estabelecimento do seu controle pelo Estado ou pelas empresas do setor. 
Os entes estatais passam pelo contínuo desafio de se adaptar às novas realidades trazidas pela globalização e sociedade de informação, em que o uso das TICs modificou a forma de como o poder público cumpre suas funções. A conformação de uma nova sociedade pautada, sobretudo, pelas facilidades no acesso à informação gerou a necessidade do Estado se adaptar a um novo contexto social.

Por isso, na maior parte dos países avançados, multiplicam-se procedimentos administrativos virtuais no sentido de simplificá-los e torná-los mais transparentes, bem como para realizar a aproximação do governo e cidadão, fundamentalmente para que o cidadão tenha uma participação democrática mais efetiva e, com isso, exercite seus direitos individuais através de instrumentos oferecidos na rede, (LÉVY, 2002, p. 102).

Esta mudança governamental quanto aos mecanismos virtuais provém, essencialmente, da sociedade, do mercado e das empresas, isso porque os atores privados se acostumaram à eficácia, agilidade e transparência da informação virtual, com isso, a ineficiência e a falta de clareza com a qual as administrações públicas transmitem seus atos torna-se chocante.

Na construção desse novo cenário, em que a fiscalização e o controle social sobre os atos estatais se intensificam, o surgimento de leis específicas que promovam o direito ao acesso à informação pública servem para assegurar e reforçar as bases institucionais do Estado democrático de Direito.

\section{APONTAMENTOS SOBRE A LEI DE ACESSO À INFORMAÇÃO COM ÊNFASE NAS TICS}

A Suécia foi o primeiro Estado a desenvolver um marco legal específico para garantir o acesso à informação governamental. A lei para a liberdade de imprensa e do direito de acesso aos atos públicos data de 1776. Atualmente, os funcionários suecos afirmam poder entregar uma cópia fiel de qualquer documento elaborado até duzentos anos atrás em 24 horas (ACKERMAN; SANDOVAL; 2005, p. 06).

No Brasil, a lei de acesso à informação (LAI) é recente, tendo sido promulgada em 18 de novembro de 2011 com a finalidade de regulamentar o inciso XXXIII do art. $5^{\circ}$ da Constituição Federal que estabelece que, todos têm direito a receber dos órgãos públicos informações de seu interesse particular ou coletivo, que serão prestadas no prazo da lei, sob 
pena de responsabilidade, ressalvadas aquelas cujo sigilo seja imprescindível à segurança da sociedade e do Estado.

Ao regulamentar esse direito, o Brasil, além de garantir o exercício do direito de acesso à informação ao cidadão, cumpriu com o compromisso assumido perante a comunidade internacional em vários tratados e convenções. A LAI simboliza uma modificação no entendimento das premissas relativas ao tema da transparência pública, uma vez que estabelece que o acesso à informação é a regra e o sigilo, a exceção.

A promulgação da lei de acesso à informação inaugurou uma nova etapa no processo de democratização na ordem jurídica pátria, pois permite e incentiva o pleno exercício da democracia, não limitando a participação popular ao voto. Com a edição da LAI o Brasil passou a integrar o rol dos países que possuem legislação específica sobre o tema.

No âmbito do MERCOSUL apenas Brasil e Uruguai têm leis específicas sobre o acesso à informação, sendo a lei uruguaia anterior à brasileira. Na Argentina a Constituição garante o direito à informação pública ao conferir aos tratados internacionais de direitos humanos hierarquia constitucional. Na seara infralegal possui somente um decreto que regula o acesso à informação restrito ao âmbito do poder executivo. A situação do Paraguai e da Venezuela é ainda mais precária nesse sentido, pois têm previsão constitucional genérica, mas nenhuma regulamentação infraconstitucional, o que torna esse direito praticamente inaplicável. (SILVA; DE LA RUE, 2013, p. 420-425).

A informação sob a guarda do Estado deve sempre ser pública, sendo o acesso restringido apenas em casos específicos. Logo, a informação produzida, guardada, organizada e gerenciada pelo Estado em nome da sociedade constitui um bem público. $\mathrm{O}$ acesso a estes dados pode ser entendido como um dos fundamentos para a consolidação da democracia, pois fortalece a capacidade dos indivíduos de participar de modo efetivo da tomada de decisões que os afeta (CONTROLADORIA GERAL DA UNIÃO, 2011, p. 08).

A LAI trouxe inovações importantes já no seu art. $1^{\circ}$, uma vez que alargou a abrangência da aplicação da lei à União, Estados, Municípios, Distrito Federal, órgãos dos Poderes Executivo, Legislativo e Judiciário, Tribunal de Contas, MP, autarquias, fundações, e até mesmo para entidades privadas que recebam recursos públicos. Estabelecer com clareza as instituições alcançadas pela lei foi de fundamental importância, uma vez que antes desse marco legal apenas o Poder Executivo se utilizava de práticas de divulgação de informações públicas, sobretudo utilizando as TICS. 
As diretrizes principiológicas básicas são elencadas no art. $3^{\circ}$, dentre elas destacamse: a publicidade da informação como regra e o sigilo como exceção; o direito do cidadão obter os dados sem a necessidade de demonstrar interesse legal.

Esses dois preceitos se coadunam com o que defende Catalina Botero, relatora especial sobre esse tema na Corte Interamericana de Direitos Humanos, quando afirma que o poder de exigir do Estado informações muda completamente a relação entre o cidadão e o Estado. A relatora apresenta algumas normas gerais que deveriam estar presentes em qualquer sistema de transparência, dentre as quais que a regra seja a transparência, sendo que qualquer exceção tem que estar concreta, precisa e claramente estabelecida na lei, sob pena do sigilo se tornar a regra. E ainda, que não é necessário demonstrar a razão de se pedir a informação, porque esse é um direito universal (BOTERO, 2014).

Nesse ínterim, as solicitações de informação feitas pelos cidadãos que antes eram vistas pelo Estado como um incômodo, hoje são reconhecidas como um direito individual que deve ser atendido pelos agentes públicos. Tal direito deriva da concepção de que o Estado trabalha para o povo e, por isso, tem a obrigação de cumprir o disposto na Constituição Federal, a qual estabelece o princípio da publicidade como dever do Estado e garantia do cidadão.

Esses são requisitos mínimos para um sistema de transparência operar positivamente. Apenas informações sigilosas, tais como de segurança nacional, é que devem permanecer no campo do segredo, isso quando efetivamente e indubitavelmente restar comprovado que a finalidade da preservação da informação é mais importante do que a sua publicação.

Importante trazer à tona o conceito de Open Government que é proveniente do Direito anglo-saxão e está relacionado diretamente com a liberdade de acesso por parte do cidadão a toda informação pública em posse do governo. Nesse sentido, em vários países houve um movimento legislativo justamente para conhecer o que a administração pública sabe sobre as pessoas, no intuito de que essa informação em poder do Estado seja divulgada de forma transparente. O máximo expoente do direito à informação nos Estados Unidos, por exemplo, é o Freedom of Information Act (FOIA). Esta lei foi promulgada em 1966 e estabelece que qualquer pessoa tem direito a solicitar acesso aos registros e a informação das agências federais, desde que estes registros não estejam protegidos por uma exceção prevista na própria FOIA.

A transparência e o acesso aos dados públicos são partes fundamentais do Open Government, uma vez que a transparência dos atos estatais tem sido uma reivindicação 
constante da sociedade civil. Esse fato tem gerado debates sobre quais informações podem ser liberadas e, especialmente, como operacionalizar essa liberação, na medida em que o objetivo final é oferecer a informação para que o cidadão possa exigir e fiscalizar os atos do Estado, na esperança de que o aumento da transparência implique em uma maior participação popular (ORTA, 2010, P. 78).

Nessa lógica, o Supremo Tribunal Federal, no SS 3902 Ag Rg, já se manifestou com base no direito à informação de atos estatais, sobre a constitucionalidade de lei municipal que previa a divulgação, em site oficial, de informações funcionais de servidores públicos, inclusive a respectiva remuneração, entendendo que tal divulgação não configurava violação à privacidade, intimidade e segurança do servidor público. O STF afirmou que há interesse coletivo no conhecimento dessas informações, uma vez que os dados dizem respeito aos agentes públicos e que seria “o preço a se pagar" pela opção de seguir em uma carreira pública no seio de um estado republicano. No caso em questão, portanto, prevaleceu o princípio da publicidade administrativa, o qual deve ser entendido como um dos meios mais efetivos de concretizar a República enquanto forma de governo.

Na conjuntura do acesso à informação enquanto impulsionador da transparência dos atos estatais, as TICs ganham destaque, principalmente por conseguir acompanhar o ritmo do desenvolvimento da complexidade da sociedade e por alcançar um número de pessoas imensamente maior que os meios tradicionais de divulgação.

Nesse sentido, a transparência pode ser entendida como um meio de luta contra a corrupção, sendo de fundamental importância a defesa da liberdade de imprensa e da independência da justiça, pois dessa forma o controle social será efetivo na esfera da Administração Pública. Com efeito, menciona SILVA:

Além do mais, o controle social da atuação política se justifica, pois à medida que os agentes públicos sabem que suas ações estão expostas à constante avaliação da sociedade há maior probabilidade do cumprimento de suas atribuições, evitando desperdícios e desvios de atuação e corrupção. $\mathrm{O}$ controle social também pode contribuir para a maior eficiência dos serviços já prestados, o que resultaria em economia aos cofres públicos e permitiria a satisfação de outros direitos fundamentais atualmente desatendidos (SILVA, 2016, p. 189). (...) Logo, pode-se considerar o direito ao acesso à informação como uma dimensão da cidadania, consistindo em condição indispensável para o fortalecimento das instituições e para a consolidação do estado democrático de direito, principalmente no contexto da sociedade em rede (SILVA, 2016, p. 191). 
Com a emergência de tantos escândalos políticos e sociais, deve-se implementar um maior rigorismo na aplicação da transparência e do controle da gestão pública, com abertura de um processo de inclusão digital para todos, sem que isso soe apenas uma utopia. Aliás, segundo Pierre Lévy:

A utopia é uma dimensão capital e fundadora da filosofia. Permite ao espírito crítico constituir-se, posto que concorre na edificação do universo de valores e de possíveis na base do qual se fazem as avaliações na cidade real. De igual maneira - e talvez sobretudo -, contribui para criar a ação. Como é obvio, a utopia do século XXI tão só pode descrever uma sociedade aberta e livre, mais aberta e mais livre do que a contemporânea (LEVY, 2014).

Permeada por esse espírito, a LAI estabeleceu no art. $8^{\circ}$, $\S 2^{\circ}$ que os órgãos e entidades públicas deverão utilizar todos os meios e instrumentos legítimos de que dispuserem, sendo obrigatória a divulgação em sítios oficiais da rede mundial de computadores. $\mathrm{O}$ artigo ainda estabelece os requisitos mínimos que os sites devem conter (isso também como medida de proteção ao direito do acesso à informação). Portanto, foi estabelecida uma obrigação para os agentes públicos, que se tornaram responsáveis por disponibilizar a informação pública na internet de forma clara e precisa de forma que qualquer cidadão consiga compreende-la.

Em outro caso mais recente, o STF reconheceu a repercussão geral no RE 865.401 que discute a possibilidade legal de um vereador formular, diretamente ao chefe do Poder Executivo, a solicitação de informações e documentos sobre a gestão municipal com a finalidade de fiscalizar possíveis irregularidades. O requerente invocou o direito fundamental de acesso à informação, do dever do poder público à transparência e dos princípios republicano e da publicidade. Já o município fundou sua defesa na ingerência indevida, na separação de poderes e na diferença entre prerrogativas da casa legislativa e dos parlamentares.

Resta acompanhar como a Corte vai se posicionar sobre os limites do direito fundamental de acesso à informação, quando envolvidas a separação de Poderes e as regras do jogo político-democrático, como as prerrogativas de minorias parlamentares exercerem o controle sobre os atos praticados pelo Executivo.

Avançando na análise pontual da lei, pode-se observar que o art. 10 da Lei 12.527/2011 trata do procedimento de acesso à informação, e dispõe que qualquer interessado poderá apresentar pedido de acesso a informações aos órgãos públicos, os quais devem 
viabilizar alternativa desse pedido de acesso através da internet. Na visão do legislador, essa possibilidade facilitaria o alcance do diploma legal, uma vez que ao propiciar esse serviço através de mecanismos virtuais o Estado reconheceria a sociedade em rede como parte atuante na fiscalização das responsabilidades a cargo do Estado.

Todos esses dispositivos legais voltados ao uso das tecnologias de informação e comunicação presentes na LAI justificam a importância que o meio virtual tem na facilitação ao acesso às informações públicas. Através da internet o número de pessoas com possibilidade de conhecer os dados em poder do Estado aumenta significativamente.

Por óbvio, não se pode pretender que toda a problemática seja resolvida simplesmente com a promulgação de uma lei ou então com o uso das novas tecnologias, mas sim que o primeiro passo foi dado rumo à transparência das informações públicas e a possibilidade de controle dos atos estatais pela sociedade.

\section{CONCLUSÃO}

As TICs devem ser utilizadas para democratizar o acesso à informação, ampliação de discussões e dinamização na prestação de serviços públicos, sempre com foco na eficiência e efetividade das funções governamentais. O fortalecimento da participação cidadã por meio do acesso a informação tem por finalidade forçar novas condutas para uma administração pública mais eficiente e transparente.

O Estado passou por profundas modificações decorrentes do fenômeno da globalização que, dentre outros fatores, impulsionou vigorosamente o uso de novas tecnologias e meios de comunicação. Por isso, é de suma importância que o poder público se adapte a essa nova realidade virtual, empenhando esforços para a otimização na prestação dos serviços públicos a seu encargo.

A lei 12.527/2011 certamente foi um avanço nesse sentido, todavia um longo caminho ainda precisa ser trilhado para a completa efetivação dos dispositivos legais. Há necessidade de um forte trabalho de inclusão digital para a população, uma vez que seria inócuo que todas as informações estivessem disponíveis na rede, como dispõe a LAI, mas que a população não tivesse capacidade para acessá-las.

A promulgação de leis específicas garantindo o acesso à informação pública visa incentivar a participação popular e o controle social dos atos estatais no sentido de efetivar 
mudanças necessárias no comportamento do poder público, que por vezes ainda é regido pela cultura do segredo. Sob esse ponto de vista, as tecnologias de informação e comunicação realmente são aptas a permitir uma mudança de paradigmas que force o Estado a adotar a transparência como regra, migrando para uma cultura de acesso às informações públicas.

\section{REFERÊNCIAS}

ACKERMAN, John M.; SANDOVAL, Irma E. Leys de Acceso a la Información em el mundo. Cuadernos de Transparencia, 07. Delegación Coyoacán, México, D.F.: Instituto Federal de Acceso a la Información Pública, 2005.

BAUMAN, Zygmunt; BORDONI, Carlo. Estado de crise. 1.ed. Rio de Janeiro: Zahar, 2016.

BARROSO, Luis Roberto. Revista Trimestral de Direito Civil. Rio de Janeiro: Padma, 2003. Ano 4. Vol. 16 out - dez.

BOTERO, Catalina. Conferencia magistral sobre el derecho de acceso a la información Intervención de Catalina Botero en el Coloquio internacional "Hacia el Sistema Nacional de Transparencia", del Instituto de Investigaciones Jurídicas de la UNAM. México, 8 de agosto de 2014. Disponível em: http://www.oas.org/es/cidh/expresion/multimedia/\#tab7. Acesso em: 18 de maio 2016.

CASTELLS, Manuel. A sociedade em rede. A era da informação: economia, sociedade e cultura. São Paulo: Editora Paz e Terra, 2008. Vol. 1.

A galáxia da internet: reflexões sobre a internet, os negócios e a sociedade. Rio de Janeiro: Zahar, 2003.

CHEVALLIER, Jacques. O estado pós-moderno. Belo Horizonte: Fórum, 2009. 
CONTROLADORIA GERAL DA UNIÃO. Acesso à informação pública: Uma introdução à lei 12.527 de 18 de novembro de 2011. Brasília, 2011. Disponível em: < http://www.acessoainformacao.gov.br/central-de-

conteudo/publicacoes/arquivos/cartilhaacessoainformacao.pdf >. Acesso em: 10 de jun. 2016.

FARIAS, Edílson. Liberdade de Expressão e Comunicação: teoria e proteção constitucional. São Paulo: Editora Revista dos Tribunais, 2004.

FLEINER, Thomas. O que são Direitos Humanos? São Paulo: Max Limonad, 2003.

LARA, Helio Cezar. Democracia e internet: as novas possibilidades na formação da opinião pública. 2013. Dissertação (Mestrado em Direito do Estado) - Faculdade de Direito, Universidade de São Paulo, São Paulo, 2013. Disponível em: $<$ http://www.teses.usp.br/teses/disponiveis/2/2134/tde-07022014-074232/>. Acesso em: 2014-10-07.

LÉVY, Pierre. Ciberdemocracia. Lisboa, Instituto Piaget, 2002.

ORTA, Carlos Guardián. Transparência? In: CALDERÓN, Cesar; LORENZO, Sebastián. Open Government. Gobierno Abierto. Granada: Algón, 2010.

PÉREZ LUÑO, Antonio Enrique. Cibercidadani@ o cidadani@.com? Barcleona: Editorial Gedisa, 2004.

ROVER, Aires. Introdução ao governo eletrônico. Revista Democracia Digital e Governo Eletrônico, v. 1, n. 1, 2009.

SALDANHA, Jânia Maria Lopes. OS DESAFIOS DO "IMPÉRIO CIBERNÉTICO” NA ERA DA ACELERAÇÃO E DA INFORMAÇÃO: Um "sexto continente" de liberdade perfeita ou de controle perfeito? In: Jerônimo Siqueira Tybusch; Luiz Ernani Bonesso de Araújo; Rosane Leal da Silva. (Org.). Direitos Emergentes na Sociedade Global. 1ed. Ijuí: Unijuí, 2013, p. 173-220. 
SANTOS, Milton. Técnica Espaço Tempo: Globalização e meio técnico-científico informacional. 5 ed. São Paulo: EDUSP, 2008.

SARLET, Ingo Wolfgang. A eficácia dos direitos fundamentais. Livraria do Advogado: Porto Alegre, 2006. $6^{\mathrm{a}}$ ed. p. 71

SILVA, Rosane Leal da. A implementação da transparência ativa pelos tribunais de justiça brasileiros: breve panorama do estado da arte. In: REDIN, Giuliana; SALDANHA, Jânia Maria Lopes; SILVA, Maria Beatriz Oliveira da. Direitos emergentes na sociedade global: Programa de Pós-Graduação em Direito da UFSM. Santa Maria: Ed. Da UFSM, 2016.

; De la Rue, Letícia Almeida. O acesso à informação pública por meio de portais como instrumento para a democratização do poder judiciário: análise comparativa nos países do MERCOSUL. In: ROVER, Aires José; SIMÃO FILHO, Adalberto; PINHEIRO, Rosalice Fidalgo. Direito e novas tecnologias. [Recurso eletrônico online]. Florianópolis: FUNJAB,2013, p. 406- 433.Disponível em: <http://www.publicadireito.com.br/artigos/?cod=3556a3018cce3076>. Acesso em: 22 jul. 2014

TAVARES, André Ramos. Liberdade de Expressão-Comunicação. In: ROCHA, Fernando Luiz Ximenes; MORAES, Filomeno. (Coord.). Direito Constitucional Contemporâneo: Estudos em Homenagem ao Professor Paulo Bonavides. Belo Horizonte: Del Rey, 2005. p54

VELOSO, Renato. Tecnologias da Informação e comunicação. São Paulo: Saraiva, 2011. 